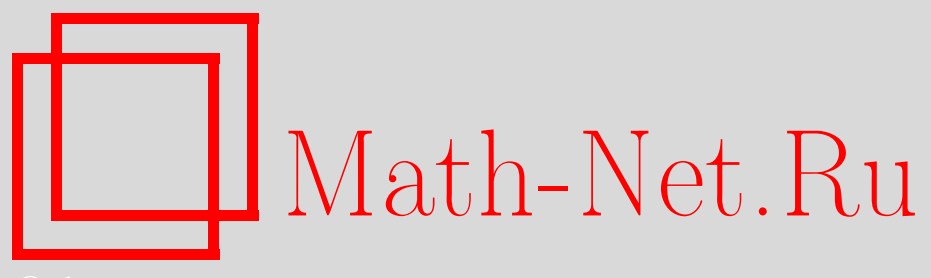

Л. Д. Беклемишев, И. Г. Лысёнок, А. А. Мальцев, С. П. Новиков, М. Р. Пентус, А. А. Разборов, А. Л. Семёнов, В. А. Успенский, Сергей Иванович Адян (к 75-летию со дня рождения), УМН, 2006, том 61, выпуск $3,179-191$

DOI: https://doi.org/10.4213/rm1750

Использование Общероссийского математического портала Math-Net.Ru подразумевает, что вы прочитали и согласны с пользовательским соглашением http://www . mathnet.ru/rus/agreement

Параметры загрузки:

IP : 52.87 .193 .239

26 апреля 2023 г., 13:14:19

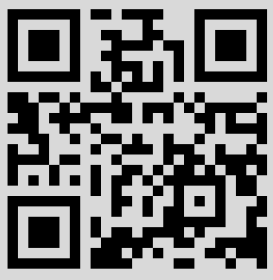




\section{МАТЕМАТИЧЕСКАЯ ЖИИНЬ}

\section{Сергей Иванович Адян}

(к семидесятипятилетию со дня рождения)

Один из крупнейших отечественных математиков академик Сергей Иванович Адян родился 1 января 1931 г. в горном селе Кущи Дашкесанского района Азербайджанской СССР, расположенном в сорока километрах от г. Кировабада (ныне Гянджа).

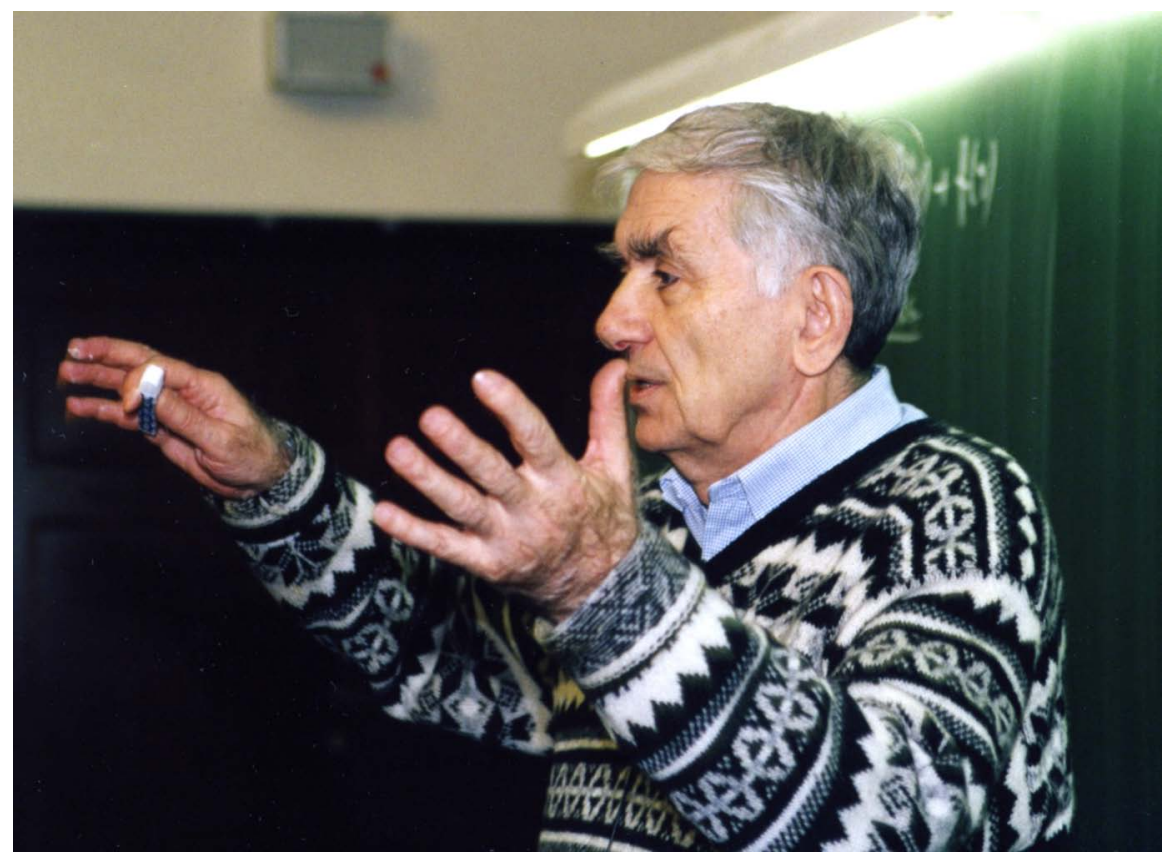

Его отец Адиян Иван Аракелович 1908 г. рождения был сыном пастуха. Не имея возможности закончить среднюю школу, он научился ремеслу плотника и работал на местных строительных площадках. В 1930 г. он женился на семнадцатилетней Лусик, дочери местного крестьянина Константина Трузьяна. Через два года родители Сережи переехали в г. Кировабад, где отец устроился на работу плотником. Сначала они снимали комнату, и только к концу 30-х годов отец купил участок в центре города и построил там небольшой домик с одной жилой комнатой, балконом и подвальчиком. Будучи сам строителем, отец планировал достроить в доме второй этаж, но помешала война. K этому времени в семье уже было четверо детей. Мама не работала, но родители завершили свое среднее образование в вечерней рабочей армянской школе. Хотя Сережа, как и его родители, не умел говорить по-русски, в 1938 г. его отдали 
учиться в русскую среднюю школу № 11 г. Кировабада. Отец настоял на этом, так как был уверен, что после ее окончания сыну будет легче получить высшее образование. Таким образом, уже с первого класса мальчику пришлось проявить упорство и трудолюбие. Проблемы с русским языком были преодолены уже к концу первого года.

В 1941 г., в самом начале войны, отец был призван в армию. Он прошел непродолжительные курсы обучения на северном Кавказе и был отправлен на фронт. Повоевать ему так и не удалось: в Крыму в районе г. Керчи из-за бездарного руководства (a, может быть, и предательства) военачальников, их подразделение оказалось в окружении в катакомбах. Семья получила извещение, что отец пропал без вести. Мама устроилась на работу продавщицей газированной воды в киоске, а 10-летний Сережа был дома за старшего, помогая матери по хозяйству и в воспитании двух младших братьев Семика (8 лет), Юрика (3 года) и сестры Светланы (6 лет).

В школе № 11, где он учился, были хорошие, а главное, требовательные учителя. Математические способности Сережи проявились рано. Однажды в четвертом классе учительница предложила, чтобы все ученики самостоятельно решали определенную задачу из задачника, а она ходила по рядам и смотрела, как у них это получается. Пока все решали первую, Сереже удалось решить уже несколько задач. Учительнице это понравилось и она продолжила эксперимент до конца урока; в результате Сережа за один урок справился с сорока задачами. Другой интересный эпизод случился в десятом классе. Учитель математики, он же директор школы, Сергей Арустамович Амбарцумян перед весенними каникулами дал задание ученикам в порядке подготовки к выпускным экзаменам порешать задачи по стереометрии с применением тригонометрии из известного задачника Рыбкина (он попросил решить по паре задач из каждого параграфа). Каково же было удивление учителя, когда через неделю его ученик Сергей Адян вручил ему толстую тетрадь с полным решением всех задач из задачника Рыбкина с чертежами. Учитель сказал, что эту тетрадь он забирает для школьного музея. Не удивительно, что после окончания средней школы Отдел народного образования г. Кировабада послал в столицу республики г. Баку ходатайство о том, чтобы Сергея Адяна послали на учебу в МГУ им. Ломоносова. Но в Баку его фамилию вычеркнули из списков направляемых на учебу в Москву. Тогда он по рекомендации директора поехал в Ереван, чтобы поступить в Ереванский университет. Но там была своя "национальная политика". Документы в университет у него не приняли, так как нужно было сдавать письменный экзамен по армянскому языку, а в Азербайджане в русской школе армянскому алфавиту, конечно, не учили. В результате в 1948 г. Сергей был вынужден поступить на учебу в Ереванский Русский педагогический институт им. Брюсова. Проучился он там всего год. После первого курса вместе с группой лучших студентов Еревана его направили для продолжения учебы в Москву. Эта акция была организована Союзным министерством образования. При этом из каждого вуза переводили в вуз того же профиля. Поэтому в переводе в МГУ ему отказали. Таким образом, по чисто формальной причине не удалась еще одна его попытка попасть в МГУ. Вот как прокомментировал сам Сергей Иванович эти эпизоды в своем выступлении на юбилейной конференции к 100-летию Людмилы Всеволодовны Келдыш: “Должен сказать, что в свое время мне крупно повезло: мне не удалось попасть в МГУ. Волею судьбы я попал в МГПИ им. В.И. Ленина, там я познакомился с Петром Сергеевичем Новиковым, а через него и с его супругой Людмилой Всеволодовной. .."

Если вообще бывают на свете встречи, которые можно определить старомодным словом "судьбоносные", то именно такой была встреча Сергея Ивановича Адяна со своим будущим учителем, наставником и, несмотря на разницу в возрасте, другом Петром Сергеевичем Новиковым. Читателю, желающему узнать об этом замечательном человеке больше, мы с удовольствием рекомендуем статьи самого Сергея Ивановича [50], [51], посвященные памяти его учителя. Из [50] можно также узнать 
о той удивительной и, к сожалению, не слишком часто встречающейся в наше время связи между учеником и учителем, сложившейся между этими двумя выдающимися личностями.

Научную работу под руководством П. С. Новикова Сергей Иванович начал в области дескриптивной теории функций. В своей первой студенческой работе 1950 г. он доказал, что график любой функции действительного переменного $f(x)$, удовлетворяющей функциональному уравнению $f(x+y)=f(x)+f(y)$ и имеющей точки разрыва, всюду плотен на плоскости. Очевидно, все непрерывные решения этого уравнения линейны. Этот результат тогда не был опубликован. Любопытно, что примерно через 25 лет американский ученый из Сиэтла профессор Эдвин Хьюит, будучи с визитом в МГУ, подарил Сергею Ивановичу оттиски своих работ, одна из которых была посвящена именно этому результату, опубликованному им намного позже.

В аспирантской работе 1953 г., относящейся к разрывным функциям, были построены такие примеры полунепрерывных функций на отрезке $[0,1]$, которые при любом разбиении этого отрезка на счетное число подмножеств $E_{i}$, имеют точки разрыва хотя бы на одном из этих подмножеств, если рассматривать их только на этом множестве. Эта работа тоже не была опубликована сразу. В 1958 г. по предложению Сергея Ивановича она была опубликована в Ученых записках МГПИ как совместная работа двух авторов [8].

Осенью 1954 г. (это был уже третий год аспирантуры) П.С. Новиков предложил Сергею Ивановичу заняться проблемой распознавания свойства единичности для конечно-определенных групп, заметив, что результаты, которые он уже получил по теории функций, вполне могут составить кандидатскую диссертацию, но эта задача интереснее, она отмечена в монографии А. Г. Куроша, является трудной и не поддается решению его методами. При этом он учитывал тот факт, что Сергей Иванович уже хорошо владел методами, используемыми Петром Сергеевичем в его тогда еще не опубликованном доказательстве неразрешимости проблемы тождества. Уже в начале 1955 г. Сергею Ивановичу удалось доказать нераспознаваемось почти всех нетривиальных инвариантных групповых свойств, в том числе нераспознаваемость изоморфности фиксированной группе $G$ для каждой группы $G$. Эти результаты составили его кандидатскую диссертацию, защищенную в 1955 г., и впервые появились в 1955 г. в виде краткой заметки в "Докладах" [1] (полный текст доказательства был двумя годами позднее опубликован в [3]). Это - один из самых замечательных, красивых и общих результатов алгоритмической теории групп, известный в настоящее время как теорема Адяна-Рабина ${ }^{1}$, и нам бы хотелось остановиться на нем подробнее.

Предположим, что у нас имеется группа $G$, заданная конечным числом образующих и определяющих соотношений в виде

$$
G=\left\langle a_{1}, \ldots, a_{m} \mid r_{1}=1, \ldots, r_{n}=1\right\rangle,
$$

где $r_{i}$ - слова в "групповом алфавите" $\left\{a_{1}, \ldots, a_{m}, a_{1}^{-1}, \ldots, a_{m}^{-1}\right\}$ (таким образом, $G$ это факторгруппа свободной группы с образующими $a_{1}, \ldots, a_{m}$ по нормальной подгруппе, порожденной элементами $\left.r_{1}, \ldots, r_{n}\right)$. Незадолго до появления работы [1] П. С. Новиков опубликовал фундаментальный (и также ставший к настоящему времени классическим) результат об алгоритмической неразрешимости в общем случае проблемы равенства слов [Nov1]. Им впервые был построен пример группы $G$, для которой невозможен алгоритм, определяющий по данному слову $r$ выполнение равенства $r=1$ в ней.

С общематематической точки зрения, однако, не менее естественным представляется вопрос об алгоритмической распознаваемости свойств самих групп $G$ как

\footnotetext{
${ }^{1}$ Американский математик М. Рабин опубликовал более простое доказательство этого результата несколькими годами позднее.
} 
абстрактных алгебраических объектов. Нетривиальные распознаваемые свойства существуют: таковым, например, является свойство " $G /[G, G]$ содержит элемент порядка 75." На таком фоне теорема Адяна-Рабина выглядит тем более удивительной, и значительной научной смелости требует уже само предположение, что нечто в этом роде вообще возможно. Не вдаваясь в технические детали, она утверждает, что экзотические примеры такого сорта являются по существу единственно возможными, и для подавляющего большинства "естественных" инвариантных групповых свойств проблема их распознавания алгоритмически неразрешима.

Конечно, в истории математики имеется довольно много других примеров студенческих или аспирантских работ, впоследствии ставших классическими результатами в своей области. Что, однако, выделяет первую опубликованную работу Сергея Ивановича [1], [3] даже в этой блестящей компании - это ее завершенность. Несмотря на многочисленные попытки, за прошедшие 50 лет никому не удалось добавить к этим результатам ничего принципиально нового. Не удивительно, что результат Сергея Ивановича был немедленно использован А. А. Марковым [Mar] для доказательства алгоритмической неразрешимости классической проблемы распознавания гомеоморфности топологических многообразий. Сам же Сергей Иванович за эту работу был награжден премией Московского математического общества (1956 г.) и премией им. П.Л. Чебышева АН СССР (1963г.). Примечателен факт, что один из официальных оппонентов кандидатской диссертации Сергея Ивановича А. С. ЕсенинВольпин летом 1955 г., прочитав и проверив диссертацию, специально приехал к П. С. Новикову на дачу, чтобы убедить его, что за такую работу следует давать докторскую степень. Петр Сергеевич ответил, что ничего страшного, он не сомневается, что Адян напишет другую работу для докторской. А первый оппонент А. И. Мальцев предложил Ученому совету МГПИ, где проходила защита, специально отметить, что эта работа выдающаяся.

После окончания аспирантуры Сергей Иванович в течении нескольких лет работал (в тесном сотрудничестве с Петром Сергеевичем Новиковым) ассистентом на кафедре математического анализа МГПИ. А в 1957 г. произошло событие, полностью изменившее жизнь как самого Сергея Ивановича, так и его учителя. А именно, в Математическом институте им. В.А. Стеклова был организован отдел математической логики, заведовать которым пригласили П. С. Новикова. Сергей Иванович стал одним из первых сотрудников вновь образованного отдела, и с ним была тесно связана его дальнейшая научная карьера. И совместная работа Петра Сергеевича и Сергея Ивановича по проблеме Бернсайда началась (приблизительно в 1960 г.) уже в стенах МИАН.

Как и многие другие великие математические проблемы, проблема Бернсайда поражает своей обманчивой простотой. Фиксируем $n \geqslant 2$ и рассмотрим группу

$$
G=\left\langle a_{1}, \ldots, a_{m} \mid X^{n}=1\right\rangle
$$

с тождеством $X^{n}=1$ (отличие от (1) состоит в том, что здесь $X-$ не фиксированное слово, а переменная, пробегающая по множеству вообще всех слов в алфавите $\left.\left\{a_{1}, \ldots, a_{m}, a_{1}^{-1}, \ldots, a_{m}^{-1}\right\}\right)$. Будет ли $G$ конечной?

В посвященной истории комбинаторной теории групп монографии [ChM] проблема Бернсайда характеризуется следующим образом:

Проблема Бернсайда явиласъ катализатором в исследованиях по теории групп аналогично "Великой теореме Ферма" в теории чисел. Проблема с весъма простой формулировкой, которая оказывается крайне трудной для решения, таит в себе нечто неотразимо притягательное для разума математика. 
До работы Новикова-Адяна положительный ответ был известен лишь для $n \in$ $\{2,3,4,6\}$, а также для матричных групп, что, впрочем, не мешало бытовать убеждению о том, что он должен быть утвердительным для любого периода $n$, и вопрос состоит лишь в нахождении правильных методов для доказательства этого предположения. Как показало развитие событий, такое убеждение оказалось весьма наивным и свидетельствует лишь о том, что до работы Новикова-Адяна никто даже приблизительно не представлял себе характер свободной бернсайдовой группы (2), и насколько тонкие структуры неизбежно возникают при любых попытках ее серьезного исследования. Фактически не было никакого метода для доказательства неравенств в группах, задаваемых тождествами вида $X^{n}=1$.

Подход к отрицателъному решению проблемы впервые был намечен П. С. Новиковым в появившейся в 1959 г. заметке [Nov2]. Однако при реализации этих идей возникли серьезные трудности, и по настоятельной просьбе Петра Сергеевича и его супруги Людмилы Всеволодовны Келдыш в 1960 г. Сергей Иванович подключился к работе по проблеме Бернсайда. Завершение этого проекта потребовало напряженной работы обоих авторов в течении 8 лет, и в 1968 г. вышла их знаменитая работа [13] с отрицательным решением проблемы для всех нечетных периодов $n \geqslant 4381$, а значит, и для всех периодов, кратных таким нечетным $n$.

Решение проблемы Бернсайда, безусловно, один из наиболее выдающихся и глубоких математических результатов прошедшего столетия. В то же время, этот результат - один из наиболее трудных (только изложение индуктивного перехода в рассматриваемой сложной индукции заняло целый выпуск 32 тома "Известий”, который даже пришлось удлинить на 30 страниц). Не будет преувеличением сказать, что во многом благодаря исключительному упорству Сергея Ивановича работу удалось довести до конца. В этой связи вспоминаются слова Петра Сергеевича Новикова о том, что более "пробивного" математика, чем Адян, он в своей жизни не встречал.

В основу доказательства теоремы Новикова-Адяна легла содержавшаяся в исходной заметке [Nov2] идея ограничить бесконечную систему определяющих соотношений бернсайдовой группы так, чтобы к ним можно было применить теорию малых сокращений Тартаковского. Это позволило бы вывести бесконечность группы из существования бесконечной последовательности Аршона, не содержащей квадратов. Однако, для реализации этого подхода потребовалось привлечение огромного количества новых идей и конструкций, из которых особо следует отметить идею глобальной классификации по рангам всех периодических слов данной степени $n$, представления бернсайдовой группы как предела бесконечной цепочки факторизаций свободной группы, а также понятие каскада. По существу речь идет о созданной Новиковым и Адяном стройной и логичной теории для исследования как самих групп (2), так и похожих на них групп "бернсайдовского типа".

В отличие от теоремы Адяна-Рабина (отличающейся, как мы писали выше, предельной законченностью), работа [13] ни в коей мере не "закрыла" проблематику. Более того, в течение более десяти лет Сергей Иванович продолжал активную работу по усовершенствованию и упрощению созданного метода, а также по приспособлению его к решению других фундаментальных проблем теории групп. В результате к началу 80-х годов, когда появились другие авторы, освоившие метод НовиковаАдяна, теория уже представляла собой мощный метод построения и исследования новых групп (как периодических, так и непериодических) с наперед заданными интересными свойствами.

Так, уже в следующем 1969 г. Сергей Иванович использовал созданную теорию для доказательства независимости системы групповых тождеств

$$
\left(x^{p n} y^{p n} x^{-p n} y^{-p n}\right)^{n}=1,
$$

где $p$ пробегает все простые числа при фиксированном $n \geqslant 1003$. Это означает, что ни одно из этих соотношений не следует из остальных. Тем самым, впервые 
были указаны простые примеры многообразий групп, которые не имеют конечного базиса, что явилось решением известной проблемы конечного базиса, поставленной Б. Нейманом (см. [17], [18]). Для доказательства этого результата была использована модификация метода, в которой используются не все периодические слова, а только те, которые удовлетворяют определенным условиям. Еще через два года Сергей Иванович опубликовал работу [19], в которой использовал новое обобщение метода Новикова-Адяна для исследования центрального расширения $A(m, n)$ бернсайдовой группы $B(m, n)$ с помощью циклической группы. Им было установлено, что в группах $A(m, n)$ при $m \geqslant 2$ и нечетных $n \geqslant 665$ пересечение любых двух нетривиальных подгрупп бесконечно. Последнее свойство является характеристическим для аддитивной группы рациональных чисел в классе коммутативных групп. Тем самым был получен положительный ответ на поставленный задолго до этого П. Г. Конторовичем вопрос о существовании некоммутативных аналогов аддитивной группы рациональных чисел. В отличие от групп рациональных чисел, которые являются локально циклическими, построенные некоммутативные аналоги могут иметь любое конечное число порождающих. Позже было доказано, что при добавлении к группе $A(m, n)$ одного определяющего соотношения $d^{n}=1$, где $d$ порождает центр группы, получается счетная группа, которая допускает только дискретную топологию. Вопрос о существовании таких групп был известен как проблема А. А. Маркова.

Все указанные результаты вошли в монографию Сергея Ивановича [22], в которой метод Новикова-Адяна был существенно упрощен и использован для более глубокого изучения строения бернсайдовых групп. Граница $n \geqslant 4381$ была уменьшена до $n \geqslant 665$ (эту оценку не удалось улучшить до сих пор). В монографии впервые было доказано, что свободные бернсайдовы группы нечетного периода $n \geqslant 665$ не только бесконечны, но и имеют экспоненциальный рост, т.е. число различных элементов группы, представимых словами данной длины $k$, растет как экспонента $a^{k}$, причем с ростом периода $n$ основание экспоненты может быть сколь угодно близко к тому, что мы имеем для абсолютно свободной группы с тем же числом порождающих. Там же было доказано, что бернсайдовы группы достаточно большого нечетного периода обладают и другими важными свойствами абсолютно свободных групп.

В работе [23] Сергей Иванович ввел понятие периодического произведения групп, которое ассоциативно и удовлетворяет условию наследственности по подгруппам, что дало решение известной проблемы А. И. Мальцева. Были установлены многие естественные свойства этой операции. Позже был получен критерий простоты периодических произведений групп, позволяющий строить бесконечные серии конечно порожденных бесконечных простых групп в многообраиях периодических групп. В работе [31] было доказано, что свободные периодические группы нечетного периода не являются аменабельными и симметричное случайное блуждание в них невозвратно.

Интересная и продуктивная модификация метода Новикова-Адяна была предложена в 1982 г. А. Ю. Ольшанским. В ней он использует геометрический язык диаграмм Ван-Кампена вместо языка формальных выводов групповых равенств из определяющих соотношений [Ol1], [Ol3]. В изложении Ольшанского определяющие соотношения добавляются по одному в каждом ранге, что существенно упрощает определения, но усложняет анализ вновь добавляемых соотношений. При этом приходится поднимать период группы примерно в $10^{10}$ раз (ср. оценки в [Lys] и в [Iv]). C помощью своей модификации А. Ю. Ольшанский впервые построил примеры бесконечных периодических групп простого периода $p \geqslant 10^{75}$, все подгруппы которых имеют порядок $p$ (так называемые “монстры Тарского" [Ol2]). Позже в работе С. И. Адяна и его ученика И. Г. Лысенка [40] было доказано, что такие примеры можно строить на базе первоначальной техники монографии [22] для любого нечетного $n \geqslant 1003$.

Наиболее важная и интригующая проблема, остававшаяся открытой после работ Новикова-Адяна - это проблема Бернсайда для достаточно больших периодов вида $n=2^{k}$, и эта проблема была независимо решена в работах С. В. Иванова [Iv] и 
И. Г. Лысёнка [Lys]. В результате им удалось доказать, что начиная с некоторого $k$, т.е. для всех $n \geqslant k$, группы $B(m, n)$ бесконечны, причем, в работе [Iv] это доказано для $k=2^{48}$, а в работе [Lys] для $k=8000$. Оказалось, что при четных $n$ свободная бернсайдова группа имеет более богатую структуру конечных подгрупп, чем при нечетных.

Все эти результаты в той или иной форме используют теорию Новикова-Адяна или ее модификации. Принципиальная открытая проблема в данной области, которая, по-видимому, потребует привлечения существенно новых идей - это случай малого периода (скажем, $n=5$ ). Более подробно с историей вопроса можно познакомиться по обзорным статьям Сергея Ивановича [32], [53].

Нет особой нужды долго говорить о том, насколько широкий резонанс вызвала работа [13]. Достаточно лишь отметить, что уже в 1970 г. (т.е. меньше, чем через два года после ее выхода на русском языке) Сергей Иванович получил приглашение выступить с секционным докладом на Международном математическом конгрессе в Ницце. А в 1999 г. эти результаты были удостоены Государственной премии РФ.

Из числа других научных интересов Сергея Ивановича особенно хотелось бы отметить продолжение активной работы над алгоритмическими проблемами для полугрупп с одним определяющим соотношением. Хорошо известно, что для групп с одним определяющим соотношением (т.е. вида (1) с $n=1$ ) разрешима проблема равенства слов $[\mathrm{Mag}]$. Довольно неожиданно оказывается, что для полугрупп аналогичная задача (а также некоторые близкие ей по духу) намного сложнее и остается открытой более полувека, хотя и здесь имеется серьезная надежда получить в конце концов положительное решение. Сергей Иванович неоднократно возвращался к этой сложнейшей проблеме на протяжении всей своей научной карьеры (а последняя работа на эту тему [55] была опубликована в прошлом году). Полученные им в этом направлении частные результаты принадлежат к числу наиболее сильных.

В 1965 г. по приглашению А. А. Маркова Сергей Иванович начал работу по совместительству на кафедре математической логики МГУ. Его работа на кафедре, обеспечивающая тесное и плодотворное сотрудничество между кафедрой и отделом математической логики МИАН, продолжается до сих пор.

В 1973 г. в связи с тяжелой болезнью Петра Сергеевича и по его личной просьбе Сергей Иванович был назначен на должность заведующего отделом. Соответствующее заявление было написано по совету директора МИАН академика И. М. Виноградова. Это время было непростым для истории отдела (да и пожалуй всей математической логики в СССР). Ни Сергей Иванович, ни его учитель, как и многие другие академики, в КПСС никогда не состояли, а на должность заведующего отделом в то время активно претендовали другие, партийные кандидаты. Читатель старшего поколения может легко себе представить какие диковинные формы эта активность приобретала, и тот факт, что здравый смысл в конце концов возобладал, лишний раз свидетельствует о том огромном доверии и уважении, которыми уже в то время пользовался Сергей Иванович. Когда на Ученом совете одним из академиков было высказано предложение уволить кандидата физ.-матем. наук Г. С. Маканина, так как он в течение ряда лет не написал докторскую диссетацию, Сергей Иванович решительно выступил в его защиту, обьяснив Ученому совету, что Маканин работает над трудной проблемой. Совет поверил ему и через пару лет Г. С. Маканин защитил блестящую докторскую диссертацию с решением проблемы распознавания разрешимости для любого уравнения в свободной полугруппе. Этот результат теперь считается классическим.

К слову сказать, аналогичный период турбулентности по похожим причинам переживала и кафедра математической логики на мехмате МГУ, когда в конце 70-х заболел заведующий кафедрой член-корр. АН СССР А. А. Марков. Во многом благодаря энергии, принципиальности и в то же время дипломатическому искусству Сергея Ивановича, для кафедры история также разрешилась благополучно. В частности, 
Сергей Иванович добился, чтобы деканат оставил работать на кафедре только что защитившего кандидатскую диссертацию А.Л. Семёнова. И здесь Сергею Ивановичу пришлось поручиться, что через несколько лет А. Л. Семенов будет доктором наук. Это предсказание также оправдалось, не говоря о том, что в течение многих лет А. Л. Семёнов был одним из самых активных и полезных преподавателей кафедры. В этом плане показательна также история с попыткой методической комиссии мехмата убрать из учебной программы факультета обязательный курс "Введение в математическую логику" на первом курсе. Проект новой программы без курса математической логики был передан в ректорат, когда Сергей Иванович узнал об этом. Он срочно связался со всеми, от кого это зависело на факультете, убедил всех и добился, чтобы программу вернули из ректората и восстановили обязательный курс логики на первом курсе. Этот курс читается до сих пор, бесспорно повышая кругозор выпускников мехмата. После кончины А. А. Маркова в 1980 г. на должность заведующего кафедрой был назначен А. Н. Колмогоров и ситуация с кафедрой стабилизировалась.

Сергей Иванович всегда уделял большое внимание укреплению отдела математической логики МИАН, подготовке научных кадров на кафедре математической логики мехмата и развитию связей между этими родственными подразделениями. На этом направлении Сергею Ивановичу удалось добиться выдающихся успехов. Под его руководстовм было подготовлено более тридцати кандидатских и докторских диссертаций. Ученики Сергея Ивановича - крупные ученые в области алгебры, математической логики и теории сложности вычислений. Наиболее сильные из них после окончания МГУ перешли на работу в отдел логики МИАН, который под руководством Сергея Ивановича превратился в один из наиболее сильных и уважаемых исследовательских центров в области логики. Его ученик А. А. Разборов - известный специалист в области теории сложности вычислений, является лауреатом премии Неванлинны и избран членом-корреспондентом РАН.

На кафедре математической логики МГУ Сергей Иванович, помимо руководства большим кафедральным семинаром совместно с В.А. Успенским, в течении многих лет ведет семинар по алгоритмическим вопросам алгебры и логики. В разные годы он также читал на факультете обязательные курсы по математической логике на первом и четвертом курсах, спецкурсы по алгоритмическим вопросам алгебры и по бесконечным периодическим группам. Сергей Иванович по существу является создателем и лидером целой научной школы в области математической логики и алгоритмических вопросов алгебры.

Помимо плодотворной научной и педагогической деятельности Сергей Иванович активно занимался редакторской и научно-организационной работой. Еще в конце 50-х годов по предложению П. С. Новикова С. М. Никольский пригласил Сергея Ивановича в РЖМАТ в качестве редактора раздела математической логики, так как там накопилась огромная масса непрореферированных статей. В кратчайший срок Сергей Иванович исправил положение с логикой в РЖМАТе, мобилизовав почти всех своих коллег на неблагодарную работу по написанию рефератов при мизерном гонораре. Примерно в это же время Сергей Иванович обратил внимание на то, что замечательный учебник по математической логике, написанный П. С. Новиковым, не издан, и студенты и аспиранты вынуждены читать его в рукописи. Петр Сергеевич объяснил, что издательство “Физматгиз" отклонило рукопись, так как им не понравилось, что в предисловии книги много раз употребляется термин "формализм Гильберта", а это рассматривалось как пропаганда вредной буржуазной философской теории. П. С. Новиков собирался вернуть издательству полученный в счет гонорара аванс. Сергей Иванович сказал, что это недопустимо и взялся помочь в переработке предисловия и в редактировании книги. Он отклонил предложение Петра Сергеевича стать соавтором учебника, и примерно через полгода вышло первое издание учебника П. С. Новикова по математической логике. Потом книга была переведена на несколько иностранных языков. 
Пожалуй, даже наиболее близкие к Сергею Ивановичу люди не взяли бы на себя смелость назвать его легким в общении человеком. Всем, кто хотя бы раз имел с ним дело, хорошо известны его принципиальность и бескомпромиссность по самым разным вопросам, а также внимательное отношение к мелочам. Однако тем, кто имел с Сергеем Ивановичем дело более тесно (а к их числу относятся и авторы данной заметки) хорошо известно и другое. Каким-то непостижимым образом в конечном итоге почти всегда оказывается, что на самом деле Сергей Иванович был прав с самого начала, а уж рациональное зерно в его аргументах находилось вообще всегда, без всяких исключений.

Весьма показательна известная история с присуждением кандидатской степени А. В. Кузнецова, который имел только шесть классов среднего образования. Это был талантливый самородок, которого привлекла на семинар по математической логике С. А. Яновская. Он получал интересные научные результаты, делал доклады на научных семинарах. Старшие коллеги (П. С. Новиков, А. И. Мальцев, А. А. Марков и С. А. Яновская) написали в ВАК ходатайство о присуждении ему кандидатской степени. Но из ВАКа был получен отказ, так как степень кандидата наук присуждает Ученый совет на основе защиты. Тогда А. И. Мальцев попросил Сергея Ивановича выяснить как можно было бы решить этот вопрос. Хотя П. С. Новиков сомневался в успехе этого дела, Сергей Иванович, уверенный в том, что справедливость должна восторжествовать, с присущим ему упорством и настойчивостью занялся этим делом. Несмотря на пассивное сопротивление самого А. В. Кузнецова, он сначала добился того, что А. В. Кузнецову ВАК разрешил сдать кандидатские экзамены и защитить диссертацию. Затем Сергей Иванович организовал прием у него экзаменов, а также написание и защиту кандидатской диссертации в МИАН. Первым официальным оппонентом на этой защите был сам Сергей Иванович. Вскоре после защиты А. В. Кузнецов был приглашен на работу в Кишинев на должность заведующего лабораторией математической логики Института математики Молдавии, где им было подготовлено много учеников, трое из которых стали докторами наук.

В течение многих лет Сергей Иванович руководил Специализированным Ученым Советом BAK по защите докторских диссертаций по специальностям: математическая логика, алгебра, теория чисел, геометрия и топология в МИАН сначала в качестве заместителя председателя, а после смерти академика И. М. Виноградова в качестве председателя. В 1991 г. он написал заявление с просьбой освободить от должности председателя Спецсовета в связи с его 60-летием. Однако, когда дирекция предложила на пост председателя Спецсовета человека, который явно не подходил для этой должности, Сергей Иванович не мог смириться с этим и заявил, что он готов остаться на этой должности, если не будет предложен более подходящий преемник. Его в этом вопросе поддержал заведующий отделом геометрии и топологии академик С. П. Новиков. Так как новая кандидатура должна была проходить через Отделение математики, то академику-секретарю Отделения математики РАН А. А. Гончару пришлось вмешаться и провести обсуждение возможных кандидатур между всеми заведующими отделами по соответствующим специальностям. В результате была найдена кандидатура, которую единодушно поддержали заведующие отделами. Она была также поддержана Отделением математики РАН и утверждена в BAKе.

Конечно, такая жизненная позиция не могла не принести Сергею Ивановичу массу неприятностей (во многом постоянным нахождением "на виду" объясняется его позднее избрание в члены Академии) и не помочь ему обзавестись большим числом недругов. Однако те же черты характера позволили ему приобрести настоящих друзей среди духовно близких людей, которым импонирует прямой и открытый нрав юбиляра.

В человеческих отношениях Сергей Иванович не хотел признавать государственных границ уже в то время, когда это было чревато самыми различными последствиями. На конгрессе в Ницце (1970 г.) он познакомился с американским математиком 
сицилийского происхождения Фрэнком Каннонито, и длящаяся с тех пор между ними дружба до самого начала перестройки была направлена, по выражению самого юбиляра, на развитие и расширение дружеских отношений между математиками СССР и США вопреки усилиям властей обеих стран по разжиганию холодной войны. Кроме Ф. Каннонито в течение нескольких десятилетий Сергей Иванович поддерживал научные контакты со многими выдающимися зарубежными учеными. Среди них В. В. Бун (Урбана, Иллинойс), А. Тарский (Беркли), К. Гёдель (Принстон), М. Холл (Лос Анжелес), В. Магнус (Нью-Йорк), Г. Баумслаг (Нью-Йорк), Д. Солитер (Торонто), С. Маклейн (Чикаго), А. Нероуд (Корнельский университет), Г. Хигман (Оксфорд), Б. Нейман (Канберра), О. Кегель (Фрайбург), Й. Меннике (Билефельд) и др.

В России и СНГ имеется огромное число людей, которые питают к Сергею Ивановичу глубокую признательность за все, что он для них сделал и продолжает делать. В первую очередь сюда относятся все его ученики (а также многие ученики его коллег, да и просто подающие надежды молодые люди). Мы все хорошо знаем, что Сергей Иванович всегда рядом и готов помочь делом или словом. В этом контексте еще раз следует вспомнить историю с фактическим спасением отдела логики в начале 70-х годов: развязка другого рода больно ударила бы по очень и очень многим. Стоит также упомянуть деятельность Сергея Ивановича в экспертном совете ВАК. В то время, когда этот орган рассматривался многими как средство партийного влияния на науку, честный и бескомпромиссный голос Сергея Ивановича также поддержал многих талантливых ученых. Сергей Иванович был одним из самых активных членов Комиссии Отделения математики Академии наук по математическому образованию с самого начала ее создания, сначала под председательством академика И. М. Виноградова, а затем - академика Л.С. Понтрягина. Здесь оказалось очень кстати его педагогическое образование в МГПИ, где педагогическую практику он проходил под руководством очень известного методиста Е. С. Березанской. Старшее поколение хорошо помнит ее знаменитый учебник по математике для пятых классов, по которому дети всей страны учились логическому мышлению в самом подходящем для этого возрасте.

У Сергея Ивановича трое взрослых детей, две дочери и сын. Сын Иван окончил механико-математический факультет МГУ. Старшая дочь Вера с отличием окончила филологический факультет МГУ, в последние годы она по контракту преподает русский язык в Лондоне. Младшая дочь Лена окончила МХПУ им. С. Г. Строганова (отделение керамики). Она занимается живописью и художественной керамикой. Неоднократно выставляла свои работы в Центральном доме художников и на выставках молодых художников России.

Мы, его ученики, друзья и коллеги, еще раз поздравляем Сергея Ивановича с днем рождения и желаем ему крепкого здоровья, счастья и дальнейших творческих успехов на благо отечественной и мировой науки.

Л. Д. Беклемишев, И. Г. Лисёнок, А.А. Малъцев, С. П. Новиков, М.Р. Пентус, А.А. Разборов, А.Л. Семёнов, В.А. Успенский

\section{Список литературы}

[Nov1] П. С. Новиков, Об алгоритмической неразрешимости проблемы тождества слов в теории групn, Труды МИАН, 44, Наука, М., 1955.

[Nov2] П. С. Новиков, "О периодических группах", Докл. АН СССР, 127 (1959), 749 752.

[Mar] А. А. Марков, "Неразрешимость проблемы гомеоморфии", Докл. АН СССР, 121:2 (1958), 218-220. 
[Mag] W. Magnus, "Das Identitätsproblem für Gruppen mit einer definierenden Relation", Math. Ann., 106 (1932), 295-307.

[ChM] Б. Чандлер, В. Магнус, Развитие комбинаторной теории групп. Очерк истории развития идей, Мир, М., 1985.

[Ol1] А. Ю. Ольшанский, "О теореме Новикова-Адяна", Матем. сб., 118:2 (1982), 203-235.

[Ol2] А. Ю. Ольшанский, "Группы ограниченного периода с подгруппами простого порядка", Алгебра и логика, 21:5 (1982), 553-618.

[Ol3] А. Ю. Ольшанский, Геометрия определяющих соотношений в группах, Наука, M., 1989.

[Iv] S. V. Ivanov, "The free burnside groups of sufficiently large exponents", Int. J. of Algebra and Computation, 4 (1994), 1-307.

[Lys] И. Г. Лысёнок, "Бесконечные бернсайдовы группы четного периода", Изв. РАН. Сер. матем., 60:3 (1996), 3-224.

\section{Список научных трудов С. И. Адяна}

[1] "Алгоритмическая неразрешимость проблем распознавания некоторых свойств групп”, Докл. АН ССCP, 103:4 (1955), 533-535.

[2] "О проблеме делимости в полугруппах", Докл. АН СССР, 103:5 (1955), 747-750.

[3] "Неразрешимость некоторых алгоритмических проблем теории групп", Труды MMO, 6 (1957), 231-298.

[4] "Роль закона сокращения при задании полугрупп с сокращением посредством определяющих соотношений”, Докл. АН СССР, 113:6 (1957), 1191-1194.

[5] "Конечно-определенные группы и алгоритмы”, Докл. АН СССР, 117:1 (1957), $9-12$.

[6] "Об алгоритмических проблемах в эффективно-полных классах групп", Докл. AH CCCP, 123:1 (1958), 13-16.

[7] "Проблема тождества для полугрупп с односторонним сокращением", Zeitschr. fur math. Log. und Grundl. der Math., 4 (1958), 66-88 (совм. с П. С. Новиковым).

[8] "Об одной полунепрерывной функции”, Ученые Записки Московского государственного педагогического института им. В. И. Ленина, 138 (1958), 3-10 (совм. с П. С. Новиковым).

[9] "О вложимости полугрупп в группы”, Докл. АН CCCP, 133:2 (1960), 255-257.

[10] "К проблеме тождества в ассоциативных исчислениях специального вида", Докл. AH CCCP, 135:6 (1960), 1297-1300.

[11] “Тождества в специальных полугруппах”, Докл. АН СССР, 143:3 (1962), 499-502.

[12] Определяющие соотношения и алгоритмические проблемы для групп и полугрупn, Труды МИАН, 85, Наука, М., 1966.

[13] "О бесконечных периодических группах. I, II, III", Изв. АН СССР. Сер. матем., 32:1 (1968), 212-244; 32:2, 251-524; 32:3, 709-731 (совм. с П. С. Новиковым).

[14] "Определяющие соотношения и проблема тождества для свободных периодических групп нечетного порядка", Изв. АН СССР. Сер. матем., 32:4 (1968), 971-979 (совм. с П. С. Новиковым).

[15] "О коммутативных подгруппах и проблеме сопряженности тождества для свободных периодических групп нечетного порядка", Изв. АН СССР. Сер. матем., 32:5 (1968), 1176-1190 (совм. с П. С. Новиковым). 
[16] "Identités dans groups", Proceedings of the International Congress of Mathematicians (Nice, 1970), 1, 263-267.

[17] "Бесконечные неприводимые системы групповых тождеств", Докл. АН СССР, 190:3 (1970), 499-501.

[18] “Бесконечные неприводимые системы групповых тождеств”, Изв. АН СССР. Сер. матем., 34:4 (1970), 715-734.

[19] “О некоторых группах без кручения”, Изв. АН СССР. Сер. матем., 35:3 (1971), $459-468$.

[20] "О подгруппах свободных периодических групп нечетного показателя", Трудъ МИАН, 112 (1971), 64-72.

[21] "О результатах П. С. Новикова и его учеников по алгоритмическим проблемам алгебры”, Труды МИАН, 133 (1973), 23-32.

[22] Проблема Бернсайда и тождества в группах, Наука, М., 1975.

[23] "О преобразованиях слов в полугруппе, заданной системой определяющих соотношений”, Алгебра и логика, 15:6 (1976), 611-621.

[24] "Периодические произведения групп", Труды МИАН, 142 (1976), 3-21.

[25] "Аксиоматический метод построения групп с заданными свойствами", УМH, $\mathbf{3 2 : 1}$ (1977), 3-15.

[26] “О простоте периодических произведений групп”, Докл. АН СССР, 241:1 (1978), $745-748$.

[27] "К проблеме равенства и делимости в полугруппах с одним определяющим соотношением”, Изв. АН СССР. Сер. матем., 42:2 (1978), 219-225 (совм. с Г. У.Оганесяном).

[28] "Classifications of periodic words and rheir application in group theory", Proceedings of the Burnside Workshop (Bielefeld, 1977), Lecture Notes in Math., 806, 1980.

[29] "On the word problem for groups defined by periodic relations", Proceedings of the Burnside Workshop (Bielefeld, 1977), Lecture Notes in Math., 806, 1980.

[30] "Нормальные подгруппы свободных периодических групп", Изв. АН СССР. Сер. матем., 45:5 (1981), 931-947.

[31] "Случайные блуждания на свободных периодических группах", Изв. АН СССР. Сер. матем., 46:6 (1982), 1139-1149.

[32] "Исследования по проблеме Бернсайда и связанным с ней вопросам", Труды МИАН, 168 (1984), 171-196.

[33] "Исследования по алгоритмическим вопросам алгебры", Труды МИАН, 168 (1984), 197-217 (совм. с Г. С. Маканиным).

[34] “Фрагменты слова $\delta$ в группе кос", Матем. заметки, 36:1 (1984), 25-34.

[35] “Экспоненциальная нижняя оценка класса нильпотентности энгелевых алгебр Ли", Матем. заметки, 39:3 (1986), 444-452 (совм. с Н. Н. Репиным).

[36] "Проблемы распознавания равенства и делимости для полугрупп с одним определяющим соотношением", Матем. заметки, 41:3 (1987), 412-421 (совм. с Г. У. Оганесяном).

[37] “Периодические группы и алгебры Ли”, УМН, 42:2 (1987), 3-68 (совм. с А. А. Разборовым).

[38] "Нижние оценки для порядков максимальных периодических групп простых периодов", Матем. заметки, 44:2 (1988), 161-176 (совм. с Н. Н. Репиным).

[39] "Upper and lower bounds for nilpotency classes of Lie algebras with Engel conditions", Proceedings of the 1987 Singapour Conference on Group Theory, Walter de Gruyter, Berlin, 1989 (with A. A. Razborov, N. N. Repin). 
[40] "О группах, все собственные подгруппы которых конечные циклические", Изв. АН СССР. Сер. матем., 55:5 (1991), 933-990 (совм. с И. Г. Лысенком).

[41] "On bounded generation of $S L(n, Z)$ ", Intetrnational Journal of Algebra and Computation, 2:4 (1992), 357-365 (with J. Mennicke).

[42] "The method of classification of periodic words and the Bernside problem", Contemporary Math., 131:1 (1992), 13-28 (with I. G. Lysionok).

[43] "On some algorithmic problems for groups and monoids", Rewriting techniques and applications (Montreal, PQ, 1993), Lecture Notes in Comput. Sci., 690, SpringerVerlag, Berlin, 1993, 289-300.

[44] "К проблеме делимости для моноидов, заданных одним соотношением", Матем. заметки, 55:1 (1994), 3-9.

[45] "Defining relations and the algebraic structure of the group $S L(2)$ over integral Hamilton quaternions", International Journal of Algebra and Computations, 7:1 (1997), 1-24 (with I. Lysionok, J. Mennicke).

[46] “Юрий Ильич Хмелевский (к 60-летию со дня рождения)", УМН, 52:4 (1997), 243-246 (совм. с В. П. Леденёвым, В. М. Тихомировым, А. А. Фридманом).

[47] “Алгоритмические проблемы для групп и полугрупп”, УМН, 55:2 (2000), 3-94 (совм. с В. Г. Дурневым).

[48] "Группы с периодическими коммутаторами", Докл. РАН, 374:2 (2000), 151-153.

[49] "On embeddings of $S L(2, \mathbb{Z})$ into quaternion groups", Matematische Zeitschrift, 238:2 (2001), 389-399 (with F. Grunewald, I. Lysionok, J. Mennicke).

[50] “K 100-летию со дня рождения Петра Сергеевича Новикова”, УМH, 56:4 (2001), $177-184$.

[51] “Мастер фундаментальных исследований”, Вестник РАН, 71:10 (2001), 922-927.

[52] "On prime quaternions, Hurwitz relations and a new operation of group extension", Proc. of the Steklov Institute of Mathematics, 242 (2003), 3-17 (with F. Grunewald, J. Mennicke).

[53] "Проблема Бернсайда о периодических группах и смежные вопросы", Современные проблемы математики (издание Математического института им. В. А. Стеклова), 1, 2003, 5-28.

[54] “Людмила Всеволодовна Келдыш (к 100-летию со дня рождения)", УМH, 60:4 (2005), 5-10 (совм. с А.А. Мальцевым, Е.В. Сандраковой, А.Б. Сосинским, А. В. Чернавским, М. А. Штанько).

[55] "Divisibility problem for one relator monoids", Theoret. Comput. Sci., 339:1 (2005), $3-6$. 